\section{§18. A Nitriding of 316 Stainless Steel in Molten Fluoride Salt by An Electrochemical Technique}

Watanabe, T. (Grad. Univ. Advanced Studies), Kondo, M., Sagara, A.

Molten salt such as $\mathrm{LiF}^{-\mathrm{BeF}_{2}}$ (Flibe) and LiF-NaF$\mathrm{KF}$ (Flinak) is known as promising tritium (T) breeder and coolant material for LHD type heliotron reactors with selfcooled liquid blanket system with high thermal efficiency in operation above $500^{\circ} \mathrm{C} .{ }^{1)}$ It has attractive safety advantages: low tritium solubility, inertness against air, inertness against water, low pressure operation, and low MHD resistance. We previously reported that the chemical stability of $\mathrm{AlN}, \mathrm{Y}_{2} \mathrm{O}_{3}, \mathrm{Er}_{2} \mathrm{O}_{3}$ and $\mathrm{Al}_{2} \mathrm{O}_{3}$ in Flinak was examined by corrosion test. ${ }^{2)}$ AlN is promising as a tritium barrier material because of better compatibility with Flinak than the other candidates. In the next stage, the formation of nitride layer on the surface of structural materials such as stainless steel and low activation steel is required for the development of the components for the system. In this present study, the nitriding process for the structural material was developed. Considering usage and maintenance of structural components in contact with molten Flibe or Flinak in the blanket system, nitriding treatment in these molten salts might be more advantageous than other vapor phase nitriding treatments such as ion nitriding and radical nitriding. Therefore, in this study, electrochemical nitriding treatment of austenitic steel material was performed in molten fluoride salt with lithium nitride $\mathrm{Li}_{3} \mathrm{~N}$.

Figure 1 illustrates the experiment setup. A binary eutectic mixture of $\mathrm{LiF}-\mathrm{KF}$ containing $\mathrm{Li}_{3} \mathrm{~N}$ (mixture ratio of $49 \mathrm{~mol} \% \mathrm{LiF}, 49 \mathrm{~mol} \% \mathrm{KF}$ and $2.0 \mathrm{~mol}^{2} \mathrm{Li}_{3} \mathrm{~N}$ ) was used as a fluoride salt. Rods of $99.99 \%$ pure aluminum were employed as counter and reference electrodes. Lithium forms aluminum-lithium alloy. The measured potential was determined by the equilibrium reaction of lithium in an aluminum-lithium alloy. A plate of austenitic stainless steel containing chromium and nickel, stainless steel 316, was employed as a working electrode and specimen for the nitriding treatment. The plate of $5 \mathrm{~mm} \times 10 \mathrm{~mm} \times 1 \mathrm{~mm}$ was firmly bound to a pure nickel rod with nickel wire. The specimen was characterized before and after the treatment. The surface structure was observed by a scanning electron microscopy (SEM). The cut specimen was embedded into resin after being treated. The cross-section, which was prepared by polishing, was analyzed by an electron probe micro analyzer (EPMA). Depth variation in the chemical composition and valence state was analyzed by an X-ray photoelectron spectroscopy (XPS). The crystal structure was characterized by an X-ray diffraction (XRD). The electrochemical measurement and treatment were carried out at $873 \mathrm{~K}$. The potentiostatic treatment for nitriding was conducted at $1.0 \mathrm{~V}$ vs. $\left(\mathrm{Li}^{+} / \mathrm{Li}\right)$ at $873 \mathrm{~K}$.

The cyclic voltammogram suggested that an irreversible nitriding reaction causes between $0.50 \mathrm{~V}$ vs. $\left(\mathrm{Li}^{+} / \mathrm{Li}\right)$ and $1.06 \mathrm{~V}$ vs. $\left(\mathrm{Li}^{+} / \mathrm{Li}\right)$ at $873 \mathrm{~K}$. It was found from EPMA analysis that nitrogen diffused from the surface to a depth of $35 \mu \mathrm{m}$ by the treatment for $100 \mathrm{~min}$. The treatment formed multilayered structure near the surface. Chromium nitride $\mathrm{CrN}$ was formed from the surface to the depth of $2 \mu \mathrm{m}$ and condensed in the layer. Comparing XRD patterns before and after the treatment as seen Fig. 2, it was revealed that the surface structure changed drastically in composition and crystal structure with nitrogen diffusion. Iron nitride $\alpha-\mathrm{Fe}_{\mathrm{x}(\mathrm{x}>8)} \mathrm{N}$ was also formed as a solid solution that nitrogen atoms are inserted between iron atoms. It was formed from the surface to a depth of $35 \mu \mathrm{m}$ as an inside diffusion layer. Although several nitride phases of chromium and iron were considered, formation of $\mathrm{CrN}$ and $\alpha-\mathrm{Fe}_{\mathrm{x}(\mathrm{x}>8)} \mathrm{N}$ was confirmed by XRD measurement and XPS analysis.

Therefore, it can be concluded that this electrochemical nitriding treatment made selective nitriding of chromium at the surface layer and deep diffusion layer of nitrogen to the depth over a few tens of mirometers. ${ }^{3)}$

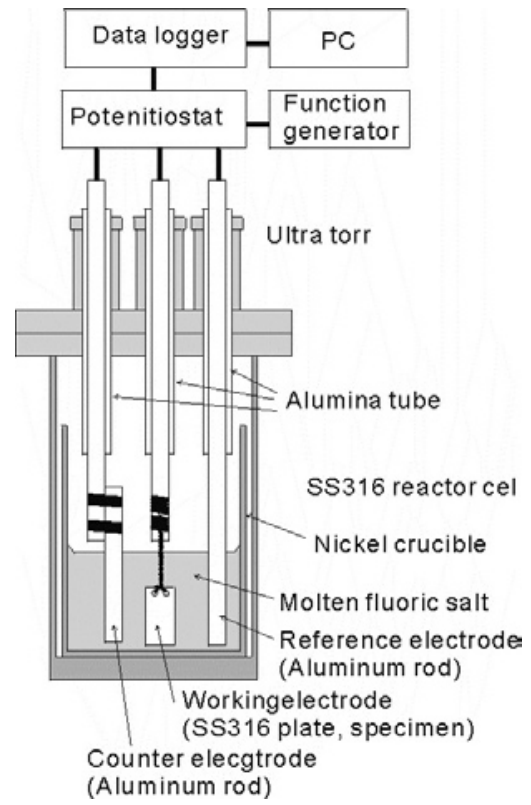

Fig. 1. Experiment setup for electrochemical measurement and treatment.

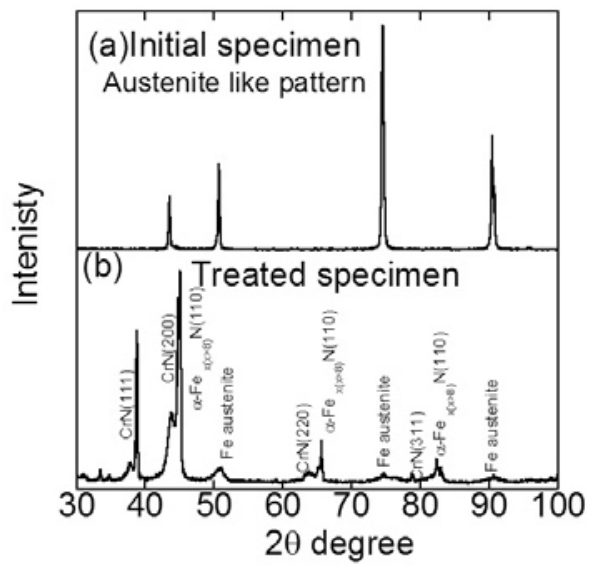

Fig. 2. XRD patterns. (a) initial specimen. (b)treated specimen.

1) Sagara, A. et al.: Nuclear Fusion 45 (2005) 258.

2) Watanabe, T. et al.: J. Plasma Fusion Res. Ser. $9(2010) 342$.

3) Watanabe, T. et al.: submitted to Electrochimica Acta. 